\title{
Article \\ Evaluation of Heteroleptic Pt (II) $\beta$-Diketonate Complexes as Precatalysts for the Photoactivated Curing of Silicone Resins
}

\author{
Maria Moro ${ }^{1}$, Paolo Zardi ${ }^{1}$ (D), Massimo Rossi ${ }^{2}$ and Andrea Biffis ${ }^{1, *(D)}$ \\ 1 Department of Chemical Sciences, University of Padova, Via Marzolo 1, 35131 Padova, Italy; \\ maria.moro@unipd.it (M.M.); paolo.zardi@unipd.it (P.Z.) \\ 2 Zhermack SpA, Via Bovazecchino 100, 45021 Badia Polesine, Italy; massimo.rossi@zhermack.com \\ * Correspondence: andrea.biffis@unipd.it; Tel.: +39-049-827-5216
}

check for

updates

Citation: Moro, M.; Zardi, P.; Rossi, M.; Biffis, A. Evaluation of Heteroleptic Pt (II) $\beta$-Diketonate Complexes as Precatalysts for the Photoactivated Curing of Silicone Resins. Catalysts 2022, 12, 307. https://doi.org/10.3390/ catal12030307

Academic Editor: Kotohiro Nomura

Received: 15 February 2022

Accepted: 5 March 2022

Published: 8 March 2022

Publisher's Note: MDPI stays neutral with regard to jurisdictional claims in published maps and institutional affiliations.

Copyright: (C) 2022 by the authors. Licensee MDPI, Basel, Switzerland. This article is an open access article distributed under the terms and conditions of the Creative Commons Attribution (CC BY) license (https:// creativecommons.org/licenses/by/ $4.0 /)$.

\begin{abstract}
A library of platinum (II) complexes of general formula $\left(\mathrm{O}, \mathrm{O}^{\prime}-\beta\right.$-diketonate $) \mathrm{PtLX}(\mathrm{L}=$ dimethylsulfoxide, pyridine, triphenylphosphine; $X=$ chloride, $\gamma$-acetylacetonate) has been prepared, using synthetic methodologies available in the literature. The library has been supplemented with a novel platinum (II) complex bearing a triazenido $N$-oxide ligand. The complexes have been characterized and tested as precatalysts for the photoactivated curing of silicone resins. Correlations have been established between the nature of the employed ligands, the ultraviolet-visible (UV-Vis) absorption spectrum of the complexes and their catalytic performance, which enable the tailored preparation of complexes with improved performance in view of possible technological applications.
\end{abstract}

Keywords: hydrosilylation; platinum; photoreduction; photodecomposition; curing; silicones

\section{Introduction}

The hydrosilylation reaction of unsaturated organic moieties, particularly $\mathrm{C}=\mathrm{C}$ double bonds, is a well-established synthetic methodology with extensive applications both in the academy and the industry [1,2]. The reaction can serve in the production of low molecular weight organosilicon compounds with applications as chemical intermediates, and in the manufacturing, chemical modification and crosslinking (curing) of silicone polymers [3,4]. Beside the more traditional thermally activated curing, research in this field has lately focused on photoactivated curing, since the mild reaction conditions that can be maintained using photoactivation enable the extension of the applicability of silicone resins to fields such as dentistry [5].

Hydrosilylation reactions require a catalyst in order to proceed at a synthetically useful rate. In this context, photoactivation involves the formation of catalytically competent species upon irradiation. Catalytic systems that can be efficiently activated by irradiation, while remaining inactive in the dark, consequently need to be identified and optimized [6]. Research in this field has largely focused on platinum compounds, given the dominant role of this metal as a hydrosilylation catalyst, in particular on platinum compound classes that obviously differ from the benchmark systems, such as the Speier catalyst and the Karstedt catalyst, that are employed in thermally activated curing reactions, since the latter are not amenable to photoactivation [4]. Two general approaches have been exploited, namely: (a) photodecomposition/photoreduction of suitable platinum (II) [7-9] and platinum (IV) [10-12] precursors to catalytically competent platinum (0) species, and (b) ligand photodissociation from a preformed, coordinatively saturated platinum (0) complex [13-15]. The former approach currently appears more promising, since ligand dissociation from platinum (0) complexes also takes place to a certain extent in the dark; consequently, it is very difficult to obtain formulations that are promptly cured by irradiation, yet also exhibit sufficient stability under dark conditions.

Several classes of compounds have been investigated in this respect, and two of them clearly emerge in this application, namely cyclopentadienyl trialkylplatinum (IV) 
compounds $[16,17]$ or bis- $\beta$-diketonate platinum (II) complexes $[8,9,18,19]$. The latter class of compounds appears particularly interesting, since it can be potentially much more extensively optimized by changing the nature of the substituents. In this connection, we have lately embarked on a systematic study aimed at evaluating the reactivity of platinum (II) compounds of general formula $\left(\mathrm{O}, \mathrm{O}^{\prime}-\beta\right.$-diketonate $) \mathrm{PtLX}$, since it has been proposed that the photoactivation process of bis- $\beta$-diketonate platinum (II) complexes goes through the removal of a $\beta$-diketonate ligand or at least through its isomerization from $\mathrm{O}, \mathrm{O}^{\prime}$-chelating bidentate to C-monodentate $[8,18,19]$. The results of this study will be presented herein.

\section{Results}

The synthesis of the target complexes moves from well-established routes that are reported in the current literature. In particular, we started by exploiting a route for the preparation of heteroleptic platinum (II) acetylacetonate complexes with DMSO (DMSO = dimethylsulfoxide), which was described by De Pascali et al., (Scheme 1) [20].

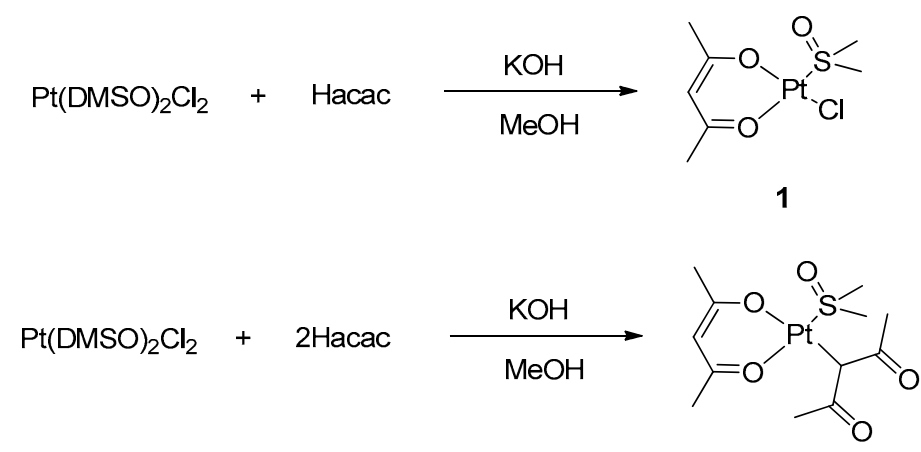

2

Scheme 1. Preparation of complexes 1 and 2.

The synthetic route proved successful and allowed for the preparation of complexes 1 and 2, depending on the stoichiometric ratio between the acetylacetonate and the platinum precursor (see Supplementary Materials). In complex 2, the complete substitution of the chloride ligands of the precursor by acetylacetonate is achieved, although one acetylacetonate ligand coordinates as a $\mathrm{O}, \mathrm{O}^{\prime}$-chelating bidentate ligand and the second one as a $\mathrm{C}$-monodentate ligand through the $\gamma$ carbon atom. Remarkably, simple $\mathrm{Pt}(\mathrm{acac})_{2}$ cannot be synthesized through this procedure.

However, the DMSO ligand in complexes $\mathbf{1}$ and $\mathbf{2}$ can be substituted by softer ligands. We performed this substitution reaction at room temperature using triphenylphosphine as the incoming ligand, obtaining complexes 3 and 4 that were previously reported by De Pascali et al., (Scheme 2, see Supplementary Materials) [21]. The reaction can easily be followed by monitoring the NMR signals of coordinated and free DMSO in the ${ }^{1} \mathrm{H}$ NMR spectrum of the compound. Incidentally, complex 4 can also be prepared upon nucleophilic attack by $\mathrm{PPh}_{3}$ on $\mathrm{Pt}(\text { acac })_{2}$ [22].

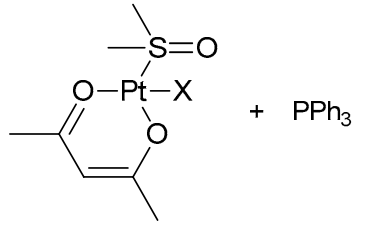

$1 \mathrm{X}=\mathrm{Cl}$

$2 \mathrm{X}=$ acac

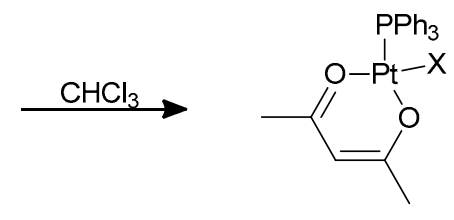

$3 \mathrm{X}=\mathrm{Cl}$

$4 \mathrm{X}=$ acac

Scheme 2. Preparation of complexes 3 and 4.

When harder neutral ligands react with complexes such as $\mathbf{1}$ and $\mathbf{2}$, they reportedly substitute preferentially the chloride ligand rather than DMSO, giving rise to monocationic 
complexes. Our targets were instead neutral platinum complexes, since they expectedly display a higher solubility in the mixture of silicone polymers that constitute the substrate for the curing reaction. Consequently, in order to prepare complexes with harder ligands, we reverted to another published procedure that moved from preformed $\mathrm{Pt}(\mathrm{acac})_{2}$ [23]. The reaction of this complex with excess pyridine resulted again in the nucleophilic attack by the incoming ligand, causing a change in coordination of the diketonate from $\mathrm{O}^{\prime} \mathrm{O}^{\prime}$-chelating bidentate to C-monodentate (Scheme 3, see Supplementary Materials). The difficulty in this reaction is the control of the number of pyridine units entering the coordination sphere of the compound: equilibrium product mixtures containing complexes $\mathbf{5}$ and $\mathbf{6}$ are obtained, which however can be easily separated, since complex $\mathbf{5}$ is soluble in diethyl ether, whereas complex 6 is not. We attempted the same synthesis using quinoline as the base, but unfortunately the reaction proved inefficient, possibly because of the greater steric bulk of the quinoline ligand.

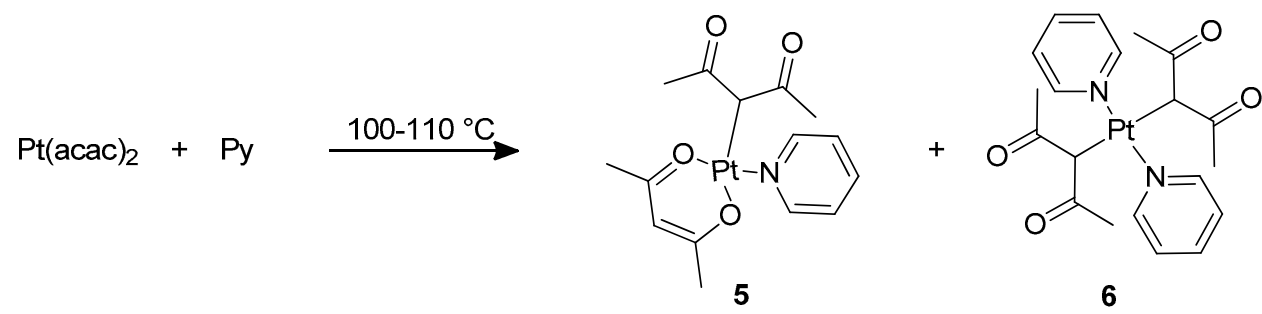

Scheme 3. Preparation of complexes 5 and 6.

The synthetic strategy described above for the preparation of complex $\mathbf{1}$ has also been recently employed to prepare an analogous Pt complex with the peculiar $\beta$-diketone curcumin [24]. Given the strong absorption of curcumin and its derivatives in the visible range, we became interested in including similar complexes in our study. However, in order to improve the stability of the curcumin ligand and to promote solubility of the complex in a comparatively hydrophobic medium such as a mixture of silicone polymers, we performed first a derivatization of curcumin by protecting the free hydroxyl groups on the aromatic rings. Silanization with t-butyldimethylsilyl (TBDMS) chloride proved successful in this respect and allowed us to subsequently prepare the platinum complex 7 with the derivatized ligand, using a unique procedure developed by us which avoided the use of water (Scheme 4).

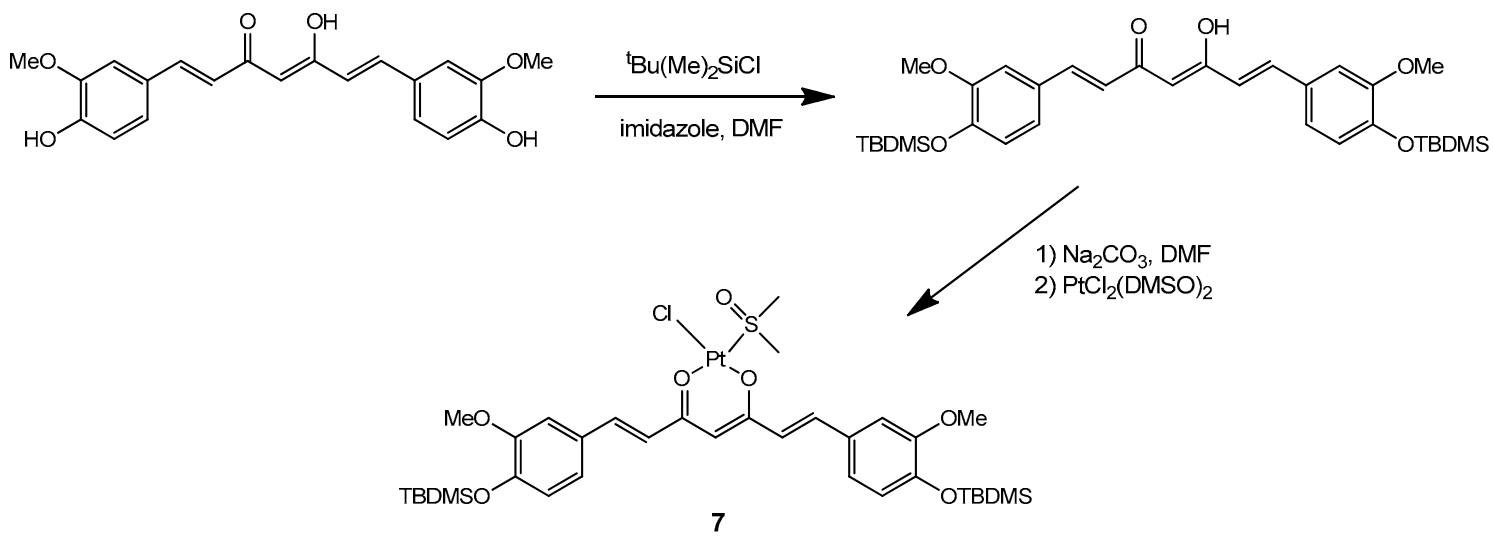

Scheme 4. Preparation of complex 7.

Finally, we attempted the exchange of the DMSO and of the chloride ligand in complex 1 with a triazenide $N$-oxide ligand. Ligands of this kind have been previously reported in the patent literature to behave as chelating ligands towards platinum and produce homoand heteroleptic complexes that can be conveniently photoactivated for hydrosilylation reactions by irradiation with UV light [25]. Thus, we conveniently synthesized by literature 
methods the triazene oxide 8 and attempted the substitution reaction. However, the reaction had an unexpected outcome, where the triazenide $N$-oxide indeed became coordinated to $\mathrm{Pt}$, yet did not substitute the DMSO and chloride ligand but rather the acetylacetonate ligand, giving rise to complex 9 (Scheme 5):<smiles>COP1(Cl)(Cl)OC(C)=CC(C)O1</smiles>

Scheme 5. Preparation of complex 9.

Several alternative strategies for the preparation of a complex containing both $\mathrm{O}, \mathrm{O}^{\prime}$ coordinated acetylacetonate and the deprotonated proligand 8 were attempted, however all resulted in no reaction or in the production of complex 9.

The UV-Vis spectra of the various complexes were recorded in order to determine their absorption wavelengths. Dichloromethane solutions $5 \times 10^{-5} \mathrm{M}$ were employed in all cases. The UV-Vis absorption spectrum of the parent $\mathrm{Pt}(\mathrm{acac})_{2}$ has been reported in the literature and exhibits absorption bands at 265, 290 and $350 \mathrm{~nm}$ [18]. Complex 1 exhibits the same three bands, but shifted at 240, 270 and $321 \mathrm{~nm}$ (Figure 1), although the low energy band is more intense compared with the one of the homoleptic acetylacetonate complex. This is relevant, as the absorption features of the compound in the spectral region above $300 \mathrm{~nm}$ will expectedly influence the efficiency of the photoactivation process, which in our study will be carried out in the near-UV as well as in the visible region. The low energy band in the UV-Vis of $\mathrm{Pt}(\mathrm{acac})_{2}$ has been proposed on the basis of a semi-empirical molecular orbital treatment to arise from a $\pi-\pi^{*}$ transition, involving the acetylacetonate ligand [26] and we assume that the analogous low energy bands displayed by all other complexes reported herein (with the only obvious exception of complex 6) originate from an electronic transition of the same nature.
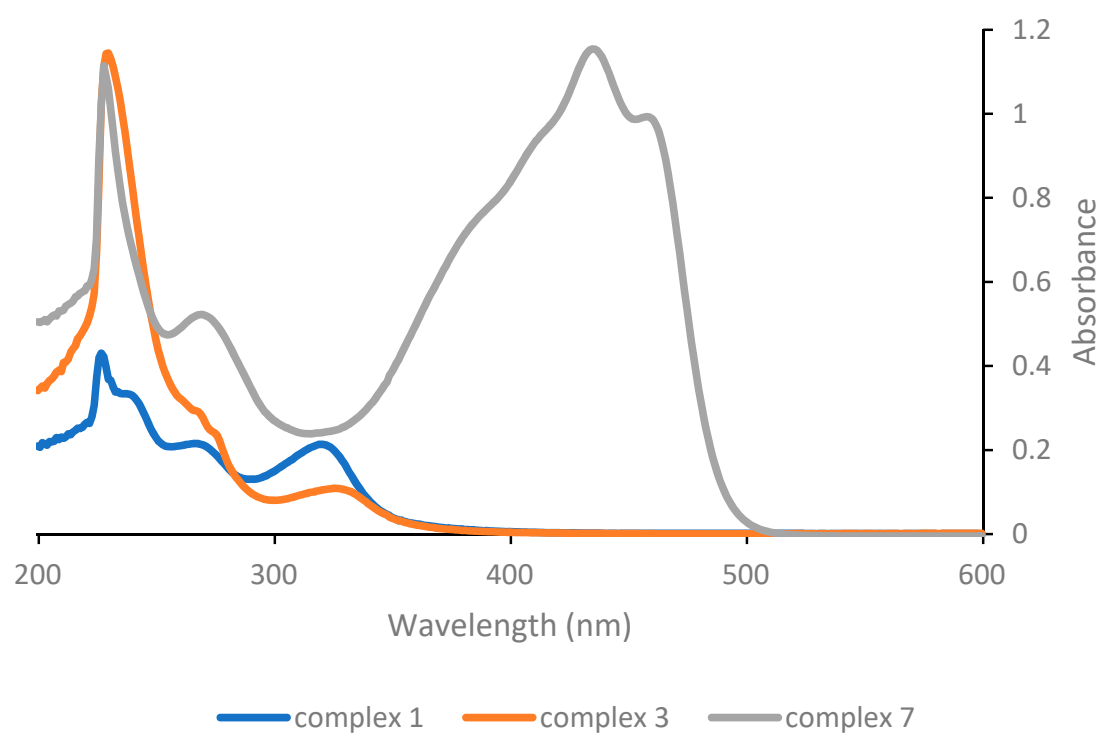

Figure 1. UV-Vis absorption spectra of complexes with general structure $\left[\mathrm{PtCl}\left(\mathrm{O}, \mathrm{O}^{\prime}-\beta\right.\right.$-diketonate $\left.) \mathrm{L}\right]$, as $5 \times 10^{-5} \mathrm{M}$ solutions in dichloromethane.

Substitution of the DMSO ligand in complex 1 with triphenylphosphine in complex 3 has significant consequences on the position and, most notably, on the intensity of the low energy band; while the maximum shifts slightly towards higher wavelengths (to $325 \mathrm{~nm}$ ), 
the intensity decreases considerably. On the other hand, substitution of the acetylacetonate ligand with the protected curcuminate ligand in complex 7 results in the appearance of a very intense and broad absorption band in the visible range, which is obviously to be attributed to the peculiar properties of the curcuminate ligand.

Considering instead the complexes of the general structure $\left[\mathrm{Pt}(\gamma\right.$-acac $)\left(\mathrm{O}, \mathrm{O}^{\prime}\right.$-acac $\left.) \mathrm{L}\right]$ (Figure 2), the low energy band is found at $307 \mathrm{~nm}$ for the parent complex 2, hence again at a much lower wavelength compared with $\mathrm{Pt}(\mathrm{acac})_{2}$ and also at significantly lower wavelengths compared with complex 1 . The effect of the change in neutral ligand $\mathrm{L}$ is somewhat more significant here, and although the absorption maximum of the low energy band remains almost unchanged (for complex 4 with $\mathrm{L}=\mathrm{PPh}_{3}$ ) or results even slightly shifted to shorter wavelengths (for complex 5 with $\mathrm{L}=$ pyridine), it turns out that in the latter case both the intensity of the absorption and the tailing towards higher wavelengths increase slightly, potentially resulting in a more efficient photoactivation of complex 5 .

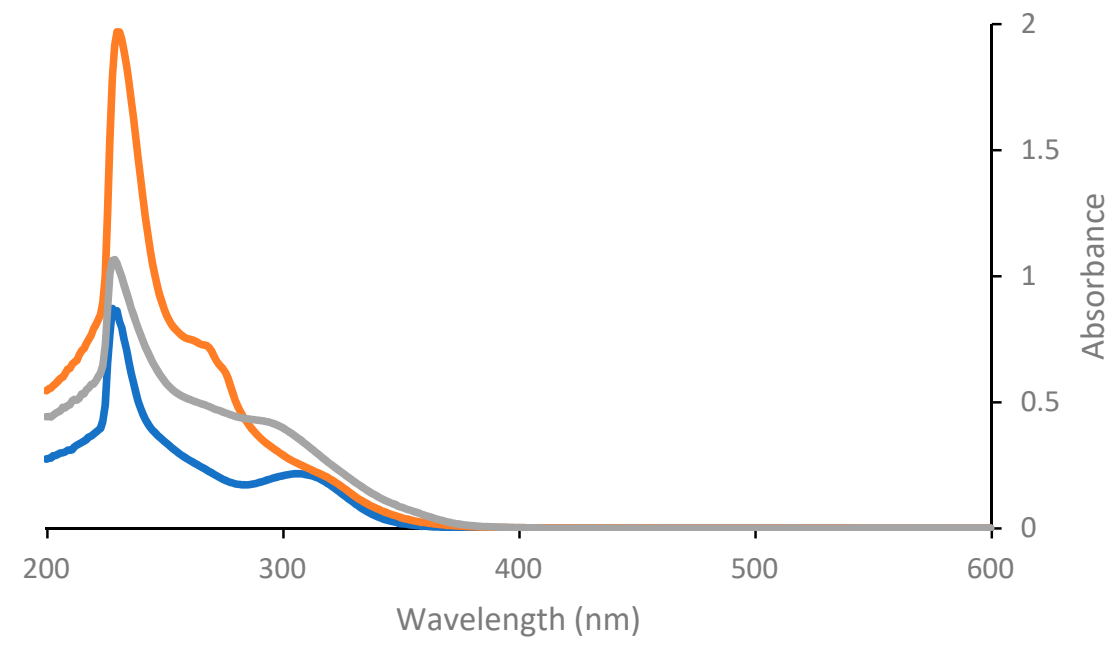

$\longrightarrow$ complex $2 \longrightarrow$ complex $4 \longrightarrow$ complex 5

Figure 2. UV-Vis absorption spectra of complexes with general structure $\left[\mathrm{Pt}(\gamma\right.$-acac $)\left(\mathrm{O}, \mathrm{O}^{\prime}\right.$-acac $\left.) \mathrm{L}\right]$ as $5 \times 10^{-5} \mathrm{M}$ solutions in dichloromethane.

Finally, considering the last complexes in the series (Figure 3), it can be appreciated that complex 6 that lacks any $\mathrm{O}, \mathrm{O}^{\prime}-\beta$-diketonate ligand exhibits a single absorption band at a low wavelength $(278 \mathrm{~nm})$ and consequently appears to not be very suitable for photoactivation in the near-UV or visible range. On the other hand, complex 9 with the triazenide- $N$-oxide ligand shows absorption features similar to the complexes with structure $\left[\mathrm{PtCl}\left(\mathrm{O}, \mathrm{O}^{\prime}-\beta-\right.\right.$ diketonate)L]. In particular, a low energy band with appreciable intensity is detected at 326 $\mathrm{nm}$, i.e., at a slightly higher wavelength compared with complex $\mathbf{1}$.

Following their UV-Vis characterization, the complexes were tested for their ability to catalyze the curing of a standard mixture of silicone polymers. The mixture was composed of a vinyl-terminated poly (dimethylsiloxane), with a viscosity of $204 \mathrm{cP}$ and a content of vinyl groups equal to $1.24 \mathrm{mmol} / \mathrm{g}$, as well as a poly (methylsiloxane) with a viscosity of $11.6 \mathrm{cP}$ and a content of hydride groups equal to $5.19 \mathrm{mmol} / \mathrm{g}$. Samples of the two polymers were mixed in order to ensure a 1:1 molar ratio between Si-H bonds and vinyl groups. The catalyst (100 ppm Pt) was pre-dissolved in 1,2-dichloroethane, quickly mixed with the silicone mixture in the dark and then subjected to irradiation or to reaction in the dark; the time needed until the mixture solidified $\left(t_{\mathrm{sol}}\right)$ was monitored. 


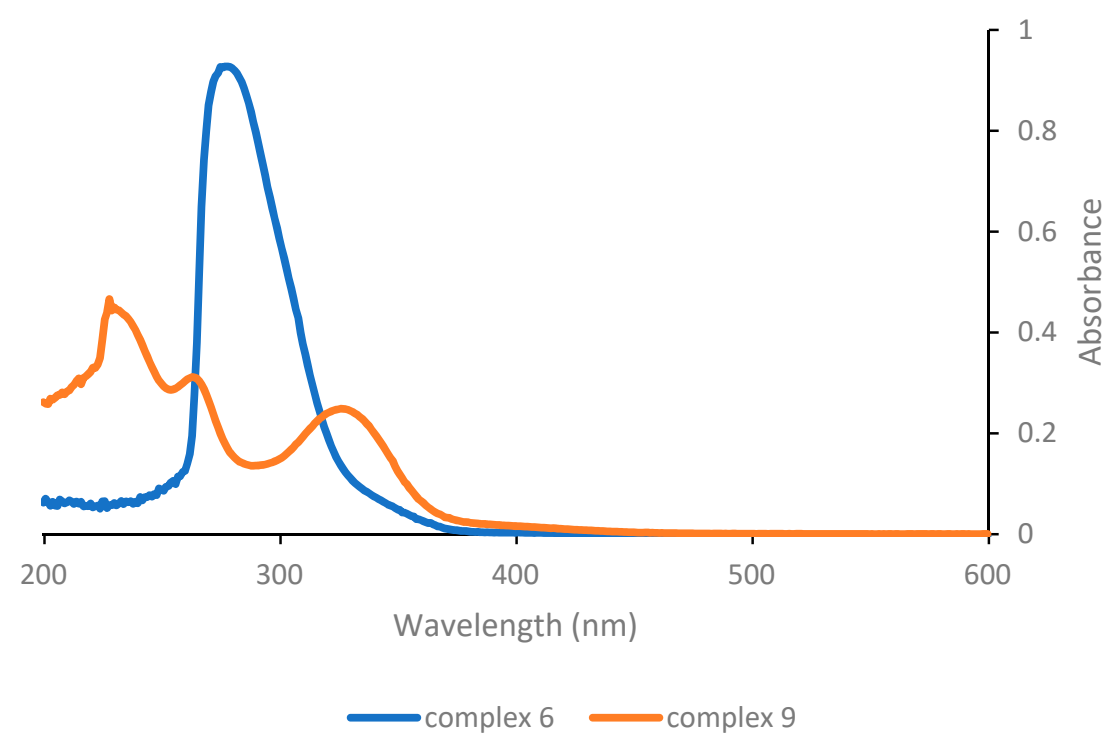

Figure 3. UV-Vis absorption spectra of complexes 6 and 9 as $5 \times 10^{-5} \mathrm{M}$ solutions in dichloromethane.

Two systems were employed for irradiation: a standard UV lamp for nail reconstruction featuring $4 \times 9 \mathrm{~W}$ bulbs irradiating in the range $340-380 \mathrm{~nm}$ and a blue LED lamp irradiating at $455 \mathrm{~nm}$ with an output power at $1.4 \mathrm{~W}$. Samples were placed at a fixed $2 \mathrm{~cm}$ or $3 \mathrm{~cm}$ distance from the light source, respectively (Figure 4). Tests were run at room temperature or, in the case of the tests in the dark, in an oven thermostated at $50{ }^{\circ} \mathrm{C}$ to speed up the process.
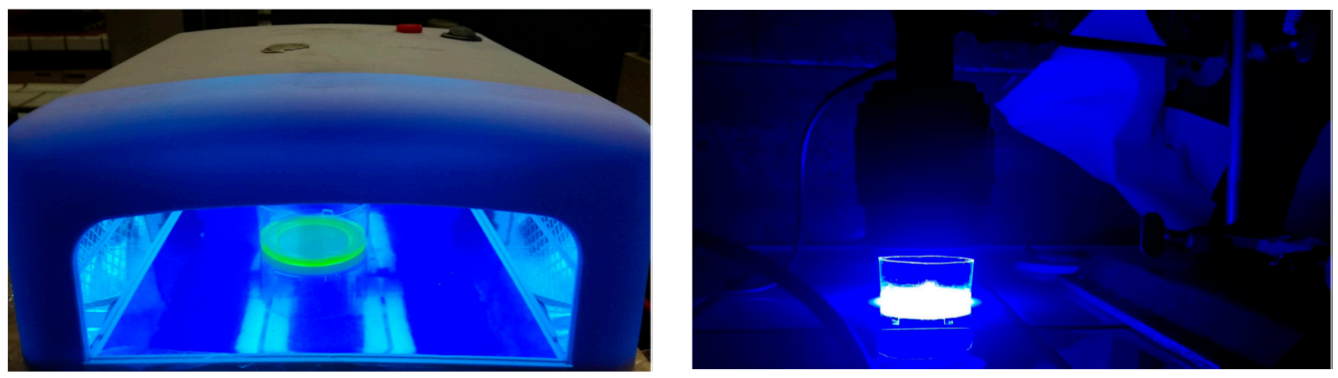

Figure 4. Experimental setup for curing experiment with UV light $(340-380 \mathrm{~nm}$, left $)$ and blue light (455 nm, right).

The results from these tests are reported in Table 1. It can be appreciated that some of the complexes with general stoichiometry $\left[\mathrm{PtCl}\left(\mathrm{O}, \mathrm{O}^{\prime}-\beta\right.\right.$-diketonate $\left.) \mathrm{L}\right]$, e.g., complexes 1 and 7, display good catalytic performance under UV irradiation, although the activity appears to be significantly lower compared with the parent $\mathrm{Pt}(\mathrm{acac})_{2}$. It must be remarked that since complex 1 presents the low energy absorption band shifted to lower wavelength compared to $\mathrm{Pt}(\mathrm{acac})_{2}$, its absorption capability in the range covered by the employed UV lamp, exemplified by $\varepsilon_{360 \mathrm{~nm}}$ reported in Table 1 , is also markedly lower. Under blue light, where nearly all the complexes show negligible absorption $\left(\varepsilon_{455 \mathrm{~nm}} \sim 10^{1} \mathrm{M}^{-1} \mathrm{~cm}^{-1}\right)$, complex $\mathbf{1}$ becomes markedly less active, whereas the performance of complex 7 is maintained and under these conditions approaches that of the reference compound. This can be explained with the exceptional light absorption capability of complex 7 at $455 \mathrm{~nm}\left(\varepsilon_{455 \mathrm{~nm}}\right.$ $19,800 \mathrm{M}^{-1} \mathrm{~cm}^{-1}$ ), which turns into an efficient activation of the catalyst even at higher wavelengths. On the other hand, and at variance with $\mathrm{Pt}(\mathrm{acac})_{2}$, these complexes are also able to efficiently promote the curing reaction under dark conditions. Apparently, the substitution of a chelating bidentate ligand such as the second $\mathrm{O}, \mathrm{O}^{\prime}-\beta$-diketonate with two monodentate ligands is detrimental for the stability of these catalyst precursors under 
dark conditions. The substitution of DMSO with $\mathrm{PPh}_{3}$ (i.e., complexes 1 vs. $\mathbf{3}$ ) results instead in a dramatic drop in catalytic activity, both under irradiation and in the dark. The reasons for this poor performance need to be further investigated, although it has been suggested that strong soft $\sigma$-donor ligands at Pt increase the stability of the catalytic system (by slowing down aggregation to Pt colloids), yet depress its activity, requiring higher reaction temperatures for a good catalytic performance $[4,5]$.

Table 1. Silicone curing tests with the various synthesized complexes as catalyst.

\begin{tabular}{|c|c|c|c|c|}
\hline Complex & $\varepsilon_{360 \mathrm{~nm}} \times 10^{-3}$ & $\begin{array}{l}\text { UV Light } \\
340-380 \mathrm{~nm}\end{array}$ & $\begin{array}{l}\text { Blue Light } \\
455 \mathrm{~nm}\end{array}$ & Dark \\
\hline & $\mathrm{M}^{-1} \mathrm{~cm}^{-1}$ & $t_{\text {sol }}(\mathrm{m})$ & $t_{\text {sol }}(\mathrm{m})$ & $t_{\text {sol }}(\mathrm{m})$ \\
\hline $\mathrm{Pt}(\mathrm{acac})_{2}$ & 3.47 & 6 & 10 & 21,600 \\
\hline 1 & 0.491 & 14 & 24 & 90 \\
\hline 2 & 0.195 & 28 & 100 & 210 \\
\hline 3 & 0.442 & 330 & $>330$ & $>7200$ \\
\hline 4 & 0.492 & 60 & $>120$ & $>1400$ \\
\hline 5 & 1.06 & 9 & 40 & $\begin{array}{c}>480 \\
63^{1}\end{array}$ \\
\hline 6 & 0.559 & 25 & 75 & 1800 \\
\hline 7 & 9.90 & 12.5 & 12.5 & 25 \\
\hline 9 & 1.31 & 19 & 27 & $50^{1}$ \\
\hline
\end{tabular}

Reaction conditions: see Section 3. ${ }^{1}$ Test carried out at $50{ }^{\circ} \mathrm{C}$.

The catalytic performance of the complexes of general stoichiometry $\left[\mathrm{Pt}\left(\mathrm{O}, \mathrm{O}^{\prime}\right.\right.$-acac $)(\gamma-$ acac)L] is also heavily dependent on the nature of the L ligand. Complex 2, in which $\mathrm{L}=\mathrm{DMSO}$, is markedly less efficient under both irradiation conditions compared with the related complex 1, which is coherent with its lower capability to absorb radiation in the near-UV and visible range; furthermore, complex 2 remains quite active in the dark. On the other hand, complex 4 , in which $\mathrm{L}=\mathrm{PPh}_{3}$, displays a catalytic performance that, although being poor in absolute terms, is evidently much better than the related complex 3 , featuring a different stoichiometry yet also bearing a $\mathrm{PPh}_{3}$ ligand. Finally, the catalytic performance of complex 5, in which $\mathrm{L}=$ pyridine, is very good under UV irradiation, although it drops considerably under blue light, again in accordance with its UV-Vis absorption features. The improved activity of complex 5 compared to 2 and 4 can be related to its slightly higher absorption in the near UV range compared with the other complexes, though the main reason for this difference is probably the absence of soft ligands in the complex coordination sphere, which tend to deactivate the catalyst. In addition, complex 5 exhibits appreciable activity in the dark, although the activity is somewhat reduced compared to the other catalyst precursors described herein. Finally, complex 6 turns out to be much less efficient than complex 5, which correlates with its lack of a $\beta$-diketonate ligand, whose cleavage is facilitated by photoexcitation, whereas complex 9 exhibits a catalytic performance very similar to complex 1, which again can be linked to the similarities in the absorption spectra of the two complexes (both exhibiting a metallacyclic ring with delocalized $\pi$-electrons) and in the identical nature of the monodentate $\mathrm{L}$ and $X$ ligands in the coordination sphere of the catalyst precursor.

Whereas, as it is sketched in the Introduction, the mechanism of the hydrosilylation reaction involves platinum (0) as a catalytically competent species and is well established, passing through oxidative addition of $\mathrm{Si}-\mathrm{H}$, olefin insertion and reductive elimination (Chalk-Harrod mechanism [27]), the photoactivation mechanism of $\beta$-diketonate platinum (II) precatalysts as those shown herein is yet to be determined with precision. Studies by Lewis et al., [18], as well as by Lavallee et al., [19] point towards two possible mechanisms, namely: direct photodecomposition to platinum $(0)$ or $\beta$-diketonate photoisomerization (from $\mathrm{O}, \mathrm{O}^{\prime}$-dicoordinated to $\mathrm{O}$ - or $\mathrm{C}$-monocoordinated) or photodissociation, both liberating coordination sites on the metal center and facilitating substitution reactions [28], which, depending on the reaction conditions and on the nature of the entering ligands, may 
ultimately lead to chemical reduction to platinum (0). The prevalence of either mechanism is considered to depend on the reaction conditions, hence further studies are needed in order to ascertain which is the most probable mechanism under our curing conditions.

In conclusion, we have demonstrated that platinum (II) complexes with general stoichiometry $\left(\mathrm{O}, \mathrm{O}^{\prime}-\beta\right.$-diketonate $) \mathrm{PtLX}$ can be tuned to efficiently act as precatalysts for the photoactivated curing of silicone resins at room temperature using blue light. Critical for success appears to be the absence of ligands $L$ with a soft character and strong $\sigma$-donating properties, which are detrimental for catalyst activity at room temperature, as well as the use of a $\beta$-diketonate ligand building up with the platinum (II) center a metallacyclic system with a more extensive electron delocalization, which shifts the absorption of the complex towards the visible range and consequently enables a more efficient photoactivation. In this respect, complexes with chloride as the $\mathrm{X}$ ligand exhibit an absorption spectrum shifted slightly more towards higher wavelengths compared with complexes in which $\gamma$-acac is the $X$ ligand, and appear consequently better suited for the scope. We are currently working towards a more extensive optimization of the ligands at platinum in order to develop a new generation of precatalysts with features surpassing the benchmark complex $\mathrm{Pt}(\mathrm{acac})_{2}$. On the other hand, platinum (II) complexes with the stoichiometry investigated herein do not ensure the stability under dark conditions that would be necessary to commercialize similar silicone mixtures as photocurable one component formulations, although it should be borne in mind that low amounts of inhibitors can be employed in this context to suppress this dark reactivity while maintaining a prompt activation under irradiation. Work aimed at the rational use of inhibitors in this context is currently underway.

\section{Materials and Methods}

All manipulations of air and moisture sensitive compounds were carried out using standard Schlenk techniques or in a glove box under an atmosphere of argon or dinitrogen. Silicone polymers were technical grade and were provided by Zhermack (Badia Polesine, Italy). Other chemicals were purchased from Merck (Darmstadt, Germany) as high-purity products and generally used as received; all solvents were purified and dried by standard methods. Complexes $\mathbf{1}$ and $\mathbf{2}$ [20], $\mathbf{3}$ and $\mathbf{4}$ [21], $\mathbf{5}$ and $\mathbf{6}$ [23] were prepared following previously published procedures. NMR spectra were recorded at $25^{\circ} \mathrm{C}$ on a Bruker (Billerica, MA, USA) Avance spectrometer working at $300 \mathrm{MHz}(300.1 \mathrm{MHz}$ for ${ }^{1} \mathrm{H}, 75.5 \mathrm{MHz}$ for ${ }^{13} \mathrm{C}$ and $121.5 \mathrm{MHz}$ for $\left.{ }^{31} \mathrm{P}\right)$. Chemical shifts $(\delta)$ are reported in units of ppm relative to the residual solvent signals and to external $85 \% \mathrm{H}_{3} \mathrm{PO}_{4}\left(\right.$ for ${ }^{31} \mathrm{P}$ ). UV-Vis analyses were carried out on a Varian Cary 100 Bio spectrophotometer. ESI-MS analyses were performed using an LCQ Duo (Thermo Finnigan, San José, CA, USA) operating in positive ion mode. Instrumental parameters were: capillary voltage $10 \mathrm{~V}$, spray voltage $4.5 \mathrm{kV}$, capillary temperature $200{ }^{\circ} \mathrm{C}$, mass scan range from 150 to $2000 \mathrm{amu}, \mathrm{N}_{2}$ was used as sheath gas, the He pressure inside the trap was kept constant. The pressure directly read by an ion gauge (in the absence of the $\mathrm{N}_{2}$ stream) was $1.33 \times 10^{-5}$ Torr. Sample solutions were prepared by dissolving the compounds in acetonitrile. Sample solutions were directly infused into the ESI source by a syringe pump at $8 \mu \mathrm{L} / \mathrm{min}$ flow rate. Elemental analyses were carried out by the microanalytical laboratory of the Chemical Sciences Department (University of Padova) with a Fisons EA 1108 CHNS-O apparatus.

\subsection{Synthesis of Complex 7}

TBDMS-protected curcumin was prepared from commercial curcumin following a published procedure [29].

$0.104 \mathrm{~g}(0.18 \mathrm{mmol})$ of TBDMS-protected curcumin was stirred with $0.023 \mathrm{~g}(0.20 \mathrm{mmol})$ $\mathrm{Na}_{2} \mathrm{CO}_{3}$ in $4 \mathrm{~mL}$ dry DMF for $20 \mathrm{~min}$. The obtained greenish solution was subsequently added dropwise to a solution of $0.0711 \mathrm{~g}(0.17 \mathrm{mmol})\left[\mathrm{PtCl}_{2}(\mathrm{DMSO})_{2}\right]$ in $2 \mathrm{~mL}$ anhydrous DMF. The resulting solution was further stirred for $3 \mathrm{~h}$ at room temperature, after which the solvent was evaporated to dryness. The resulting solid was treated with $3 \mathrm{~mL}$ dichloromethane, solid residues were filtered off, the liquid was again evaporated to dry- 
ness and the resulting solid was recrystallized from diethyl ether/hexane. Yield $30 \mathrm{mg}$ $(19.5 \%)$.

${ }^{1} \mathrm{H} \mathrm{NMR}\left(\mathrm{CDCl}_{3}\right): 7.72\left(\mathrm{~d}, 1 \mathrm{H}\right.$, vinyl- $\left.\mathrm{H}^{\mathrm{b}},{ }^{3} \mathrm{~J}_{\mathrm{HH}}=14 \mathrm{~Hz}\right), 7.57\left(\mathrm{~d}, 1 \mathrm{H}\right.$, vinyl- $\mathrm{H}^{\mathrm{b}^{\prime}},{ }^{3} \mathrm{~J}_{\mathrm{HH}}=$ $14 \mathrm{~Hz}), 7.07(\mathrm{~m}, 4 \mathrm{H}, \mathrm{Ph}), 6.86(\mathrm{~m}, 2 \mathrm{H}, \mathrm{Ph}), 6.53\left(\mathrm{~d}, 1 \mathrm{H}\right.$, vinyl- $\left.\mathrm{H}^{\mathrm{a}},{ }^{3} \mathrm{~J}_{\mathrm{HH}}=16 \mathrm{~Hz}\right), 6.51$ $\left(\mathrm{d}, 1 \mathrm{H}\right.$, vinyl- $\left.\mathrm{H}^{\mathrm{a}^{\prime}},{ }^{3} \mathrm{~J}_{\mathrm{HH}}=16 \mathrm{~Hz}\right), 5.86(\mathrm{~s}, 1 \mathrm{H}, \mathrm{OCCHCO}), 3.86\left(\mathrm{~m}, 6 \mathrm{H}, \mathrm{OCH}_{3}\right), 3.56(\mathrm{~m}$, $\left.6 \mathrm{H}, \mathrm{CH}_{3} / \mathrm{DMSO}, \mathrm{J}_{\mathrm{HPt}}=11 \mathrm{~Hz}\right), 1.01\left(\mathrm{~s}, 18 \mathrm{H},{ }^{\mathrm{t}} \mathrm{BuSi}\right), 0,19$ (broad s, $\left.12 \mathrm{H}, \mathrm{MeSi}\right) .{ }^{13} \mathrm{C} \mathrm{NMR}$ $\left(\mathrm{CDCl}_{3}\right): 175.91,175.52,150.64,150.61,146.80,146.77,141.47,140.66,128.59,122.39,121.92$, $121.45,121.38,120.64,110.71,110.48,103.51,54.90,44.28,44.22,25.09,17.93$. ESI-MS (positive ions, $\left.\mathrm{CH}_{3} \mathrm{CN}\right) ; \mathrm{m} / z: 927.00[\mathrm{M}+\mathrm{Na}]^{+}, 1830.83\left[\mathrm{M}_{2}+\mathrm{Na}\right]^{+}$. Elemental analysis calcd. for $\mathrm{C}_{35} \mathrm{H}_{53} \mathrm{ClO}_{7} \mathrm{PtSSi}_{2}: \mathrm{C}=46.47 \%, \mathrm{H}=5.91 \%, \mathrm{~S}=3.54 \%$; found: $\mathrm{C}=46.77 \%, \mathrm{H}=5.68 \%$, $\mathrm{S}=3.69 \%$.

\subsection{Synthesis of Complex 9}

Triazene oxide ligand precursor 8 was prepared using a literature procedure [30]. $20.6 \mathrm{mg}$ triazene oxide precursor 8 was suspended in $0.6 \mathrm{~mL}$ ethanol and $0.04 \mathrm{~mL}$ of a $20 \%$ solution of $\mathrm{KOH}$ in methanol (119.0 $\mathrm{mg} \mathrm{KOH}$ in $0.6 \mathrm{~mL} \mathrm{MeOH}$ ) was added. The mixture was stirred for $30 \mathrm{~min}$ and changed in aspect from a violet suspension to a greenishyellow solution. $0.45 \mathrm{~mL}$ of this solution was subsequently added to a suspension of complex 1 (23 mg, $0.064 \mathrm{mmol})$ in $1 \mathrm{~mL}$ ethanol and stirred for $1 \mathrm{~h}$ yielding a dark yellow suspension. Stirring was continued overnight, after which the solid was decanted, washed with additional ethanol and dried. Yield $15.3 \mathrm{mg}(52 \%)$.

${ }^{1} \mathrm{H} \mathrm{NMR}\left(\mathrm{CDCl}_{3}\right): 7.24$ (d, 2H), $7.13(\mathrm{~d}, 2 \mathrm{H}), 3.98(\mathrm{~s}, 3 \mathrm{H}), 3.45\left(\mathrm{~s}, 6 \mathrm{H}, \mathrm{J}_{\mathrm{H}-\mathrm{Pt}}=18 \mathrm{~Hz}\right)$, 2.34 (s, 3H). ${ }^{13} \mathrm{C}$ NMR $\left(\mathrm{CDCl}_{3}\right): 135.47,129.40,128.31,123.33,43.87,41.44,20.46$. ESI-MS (positive ions, $\mathrm{CH}_{3} \mathrm{CN}$ ); $m / z: 494.37\left[\mathrm{M}+\mathrm{H}_{2} \mathrm{O}+\mathrm{Na}\right]^{+}$, $510.39\left[\mathrm{M}+\mathrm{H}_{2} \mathrm{O}+\mathrm{K}\right]^{+}$. Elemental analysis calcd. for $\mathrm{C}_{10} \mathrm{H}_{16} \mathrm{ClN}_{3} \mathrm{O}_{2} \mathrm{PtS}: \mathrm{C}=25.40 \%, \mathrm{H}=3.41 \%, \mathrm{~N}=8.89 \%, \mathrm{~S}=6.78 \%$; found: $\mathrm{C}=25.56 \%, \mathrm{H}=3.66 \%, \mathrm{~N}=8.55 \%, \mathrm{~S}=6.59 \%$.

\subsection{Curing Tests}

General procedure. Vinyl-terminated poly-dimethylsiloxane (204 cP viscosity, $1.24 \mathrm{mmol} / \mathrm{g}$ vinyl groups content) was mixed with poly-methylsiloxane $(11.6 \mathrm{cP}$ viscosity, $5.19 \mathrm{mmol} / \mathrm{g}$ hydride groups content) in a 22:1 weight ratio, corresponding to a $1: 1$ ratio between vinyl and hydride groups. The catalyst $(100 \mathrm{ppm} \mathrm{Pt}$ with respect to the silicone mixture) was pre-dissolved in 1,2-dichloroethane ( $0.5 \mathrm{~mL}$ per $10 \mathrm{~g}$ silicone mixture) and then quickly mixed mechanically with the silicone mixture in the dark. The mixture was subsequently transferred in open low-rim cylindrical plastic containers to form an $0.5 \mathrm{~cm}$ thick layer, placed in a hood shielded from light and continuously irradiated using either a standard UV lamp for nail reconstruction featuring $4 \times 9 \mathrm{~W}$ bulbs irradiating in the range $340-380 \mathrm{~nm}$ or a blue LED lamp irradiating at $455 \mathrm{~nm}$ with an output power at $1.4 \mathrm{~W}$. Samples were placed at a fixed $2 \mathrm{~cm}$ or $3 \mathrm{~cm}$ distance from the light source, respectively. Alternatively, samples were placed in a light-shielded oven and either left at room temperature or thermostated at $50{ }^{\circ} \mathrm{C}$ for the dark tests. The solidification time $t_{\text {sol }}$ was determined by regularly checking the samples until the mixture was no longer free flowing.

Supplementary Materials: The following supporting information can be downloaded at: https: //www.mdpi.com/article/10.3390/catal12030307/s1, Additional experimental procedures and complex characterization data.

Author Contributions: Investigation, M.M. and P.Z.; resources, validation, M.R.; supervision, writing, project administration, A.B. All authors have read and agreed to the published version of the manuscript.

Funding: This research was jointly funded by Zhermack SpA and the University of Padova (UniImpresa 2018 project "PHOTOSIL"). 
Data Availability Statement: The data presented in this study are available in the article and in the Supplementary Materials.

Conflicts of Interest: The authors declare no conflict of interest.

\section{References}

1. Troegel, D.; Stohrer, J. Recent Advances and Actual Challenges in Late Transition Metal Catalyzed Hydrosilylation of Olefins from an Industrial Point of View. Coord. Chem. Rev. 2011, 255, 1440-1459. [CrossRef]

2. Nakajima, Y.; Shimada, S. Hydrosilylation Reaction of Olefins: Recent Advances and Perspectives. RSC Adv. 2015, 5, $20603-20616$. [CrossRef]

3. Hofmann, R.; Vlatković, M.; Wiesbrock, F. Fifty Years of Hydrosilylation in Polymer Science: A Review of Current Trends of Low-Cost Transition-Metal and Metal-Free Catalysts, Non-Thermally Triggered Hydrosilylation Reactions, and Industrial Applications. Polymers 2017, 9, 534. [CrossRef] [PubMed]

4. Lukin, R.Y.; Kuchkaev, A.M.; Sukhov, A.V.; Bekmukhamedov, G.E.; Yakhvarov, D.G. Platinum-Catalyzed Hydrosilylation in Polymer Chemistry. Polymers 2020, 12, 2174. [CrossRef] [PubMed]

5. Wang, D.; Klein, J.; Mejía, E. Catalytic Systems for the Cross-Linking of Organosilicon Polymers. Chem. Asian J. 2017, 12, 1180-1197. [CrossRef] [PubMed]

6. de Vekki, D.A. Hydrosilylation on Photoactivated Catalysts. Russ. J. Gen. Chem. 2011, 81, 1480-1492. [CrossRef]

7. Prignano, A.L.; Trogler, W.C. Silica-Supported Bis(Trialkylphosphine)Platinum Oxalates. Photogenerated Catalysts for Hydrosilylation of Olefins. J. Am. Chem. Soc. 1987, 109, 3586-3595. [CrossRef]

8. Lewis, F.D.; Salvi, G.D. Platinum(II) Bis(.Beta.-Diketonates) as Photoactivated Hydrosilation Catalysts. Inorg. Chem. 1995, 34, 3182-3189. [CrossRef]

9. Guo, A.; Fry, B.E.; Neckers, D.C. Highly Active Visible-Light Photocatalysts for Curing a Ceramic Precursor. Chem. Mater. 1998, 10, 531-536. [CrossRef]

10. Lippert, T.; Dauth, J.; Deubzer, B.; Weis, J.; Wokaun, A. Photolysis of an Arylalkyl-Triazenido-Platinum-IV Complex. Radiat. Phys. Chem. 1996, 47, 889-897. [CrossRef]

11. Mayer, T.; Burget, D.; Mignani, G.; Fouassier, J.P. Photohydrosilylation reaction of silicone polymers. Platinum-based photocatalysts: Trimethyl( $\beta$-dicarbonyl) platinum IV complexes. J. Polym. Sci. A 1996, 34, 3141-3146. [CrossRef]

12. Marchi, S.; Sangermano, M.; Meier, P.; Kornmann, X. Visible Light-Activated Hydrosilation Reaction. J. Photochem. Photobiol. A Chem. 2015, 303-304, 86-90. [CrossRef]

13. Meuser, R.; Mignani, G. Platinum complexes and light-activatable hydrosilylation catalysts containing same. Patent application WO199502 5734A1, 1995.

14. Buchner, M.R.; Bechlars, B.; Ruhland, K. A New Approach to Light-Gated Pt Catalysts for the Hydrosilylation. J. Organomet. Chem. 2013, 744, 60-67. [CrossRef]

15. Kaur, B.; Raza, R.; Stashick, M.J.; Branda, N.R. Using Light to Control the Inhibition of Karstedt's Catalyst. Org. Chem. Front. 2019, 6, 1253-1256. [CrossRef]

16. Boardman, L.D. ( 7 -Cyclopentadienyl)trialkylplatinum photohydrosilylation catalysts. Mechanism of active catalyst formation and preparation of a novel bis(silyl)platinum hydride. Organometallics 1992, 11, 4194-4201. [CrossRef]

17. Jakubek, V.; Lees, A.J. Quantitative Photochemistry of $\mathrm{Cp}^{\prime} \mathrm{Pt}\left(\mathrm{CH}_{3}\right)_{3}\left(\mathrm{Cp}^{\prime}=\eta^{5}-\mathrm{C}_{5} \mathrm{H}_{4} \mathrm{CH}_{3}\right)$ in Solution: A Highly Efficient Organometallic Photoinitiator for Hydrosilylation. Inorg. Chem. 2004, 43, 6869-6871. [CrossRef]

18. Lewis, F.D.; Miller, A.M.; Salvi, G.D. Spectroscopy and Photochemistry of Nickel(II), Palladium(II), and Platinum(II).Beta.Diketonates. Inorg. Chem. 1995, 34, 3173-3181. [CrossRef]

19. Lavallee, R.J.; Palmer, B.J.; Billing, R.; Hennig, H.; Ferraudi, G.; Kutal, C. Efficient Substitutional Photochemistry of a Third-Row Transition Metal $\beta$-Diketonate Complex. Inorg. Chem. 1997, 36, 5552-5558. [CrossRef]

20. De Pascali, S.A.; Papadia, P.; Ciccarese, A.; Pacifico, C.; Fanizzi, F.P. First Examples of B-Diketonate Platinum( II ) Complexes with Sulfoxide Ligands. Eur. J. Inorg. Chem. 2005, 2005, 788-796. [CrossRef]

21. De Pascali, S.A.; Papadia, P.; Capoccia, S.; Marchiò, L.; Lanfranchi, M.; Ciccarese, A.; Fanizzi, F.P. Hard/Soft Selectivity in Ligand Substitution Reactions of $\beta$-Diketonate Platinum(II) Complexes. Dalton Trans. 2009, 7786-7795. [CrossRef] [PubMed]

22. Ito, T.; Kiriyama, T.; Yamamoto, A. Studies on the Reactions of Bis(Acetylacetonato)Platinum(II) with Lewis Bases. I. Reactions with Tertiary Phosphines Leading to a Complex Containing Carbon-Bonded Unidetate Acetylacetonato Ligand and Preparation of New Alkylplatinum Complexes. Bull. Chem. Soc. Jpn. 1976, 49, 3250-3256. [CrossRef]

23. Ito, T.; Kiriyama, T.; Nakamura, Y.; Yamamoto, A. Studies on the Reacions of Bis(Acetylacetonato)Platinum(II) with Lewis Bases. II. Reaction with Pyridine Leading to Complexes Containing Uni- and Bis-Carbon Bonded Acetylacetonato Ligand(s). Bull. Chem. Soc. Jpn. 1976, 49, 3257-3264. [CrossRef]

24. Censi, V.; Caballero, A.B.; Pérez-Hernández, M.; Soto-Cerrato, V.; Korrodi-Gregório, L.; Pérez-Tomás, R.; Dell’Anna, M.M.; Mastrorilli, P.; Gamez, P. DNA-Binding and in Vitro Cytotoxic Activity of Platinum(II) Complexes of Curcumin and Caffeine. J. Inorg. Biochem. 2019, 198, 110749. [CrossRef] [PubMed]

25. Dauth, J.; Wolferseder, J.; Deubzer, B. Triazenoxid-Übergangsmetall-Komplexe Als Hydrosilylierungskatalysatoren. EP Patent 0690067, 24 May 2000. 
26. Lewis, F.D.; Salvi, G.D.; Kanis, D.R.; Ratner, M.A. Electronic Structure and Spectroscopy of Nickel(II), Palladium(II), and Platinum(II) Acetylacetonate Complexes. Inorg. Chem. 1993, 32, 1251-1258. [CrossRef]

27. Chalk, A.J.; Harrod, J.F. Homogeneous Catalysis. II. The Mechanism of the Hydrosilation of Olefins Catalyzed by Group VIII Metal Complexes. J. Am. Chem. Soc. 1965, 87, 16-21. [CrossRef]

28. Wang, F.; Wu, X.; Finnen, D.C.; Neckers, D.C. Photochemical Reactions of Platinum(II) Bis(Acetylacetonato) with Nitrogen Containing Lewis Bases. Tetrahedron Lett. 2000, 41, 7613-7617. [CrossRef]

29. Somsakeesit, L.; Senawong, T.; Kumboonma, P.; Saenglee, S.; Samankul, A.; Senawong, G.; Yenjai, C.; Phaosiri, C. Influence of Side-Chain Changes on Histone Deacetylase Inhibitory and Cytotoxicity Activities of Curcuminoid Derivatives. Bioorganic Med. Chem. Lett. 2020, 30, 127171. [CrossRef]

30. Elkins, M.; Hunter, L. 252. The Azo-Group as a Chelating Group. Part III. Metallic Derivatives of Hydroxytriazens. J. Chem. Soc. 1938, 1346-1350. [CrossRef] 